\title{
International impact of external reference pricing: should national policy-makers care?
}

\author{
Anna-Maria Fontrier ${ }^{1} \cdot$ Jennifer Gill ${ }^{1} \cdot$ Panos Kanavos $^{1}$
}

Received: 17 September 2018 / Accepted: 29 May 2019 / Published online: 9 July 2019

๑) Springer-Verlag GmbH Germany, part of Springer Nature 2019

\begin{abstract}
Background External reference pricing (ERP) is widely used to regulate drug prices. Although the literature has largely focused on the impact of ERP on a number of policy endpoints and its impact from a geographical perspective, a comparative study drawing on evidence from different settings does not exist to date.

Methods A systematic literature review was conducted on pre-defined endpoints on the impact of ERP across countries, such as price stability, price convergence and launch delays. Expert consultation was undertaken to analyse whether or not the international implications of ERP are considered during its design.

Results 46 studies were included in the analysis. Across countries, ERP may cause launch delays, price instability and lead to price convergence. However, these effects cannot be solely attributed to ERP, as there may be other factors at play, such as the size and the GDP of a country and other regulations in place, which can trigger these effects or reduce their effect. Nevertheless, the nature of ERP facilitates these unintended consequences and directly links them to it. Despite these crosscountry implications being well known to decision-makers, they are not necessarily considered during the design of ERP. Conclusions As the effects of ERP as a stand alone policy are very difficult to isolate in the presence of other regulatory measures implemented within countries and the presence of other extrinsic factors across countries, our findings are inconclusive. Still, there is an unquestionable unmet need related to the design of ERP systems to attain a positive impact internationally.
\end{abstract}

Keywords External reference pricing $\cdot$ Pharmaceutical pricing $\cdot$ Pharmaceutical policy $\cdot$ Systematic review $\cdot$ Regulation of pharmaceuticals $\cdot$ Expert consultation

JEL Classification I $\cdot \mathrm{I} 1 \cdot \mathrm{I} 10 \cdot \mathrm{I} 11 \cdot \mathrm{I} 18$

\section{Introduction}

External price referencing (ERP) is defined as "the practice of using the price(s) of a medicine in one or more countries in order to derive a benchmark or reference price for the purpose of setting or negotiating the price of the product in a given country" [1]. Over time, ERP has been considered to be a powerful tool that influences prices at national and international level, due to the interlinking of prices and path dependency, in that the features of an ERP system

Anna-Maria Fontrier

a.fontrier@1se.ac.uk

1 Department of Health Policy and LSE Health- Medical Technology Research Group, London School of Economics and Political Science, Houghton Street, London WC2A 2AE, UK influence the overall outcome within and across countries [2-5]. Despite the extensive implementation of ERP over a long time period, many countries have started to rely on other methods to inform prices, such as cost-effectiveness analysis, price negotiations and Managed Entry Agreements (MEAs) [6]. This is because several shortcomings have been identified with the use of ERP in different settings, including, among others, the fact that prices taken as reference do not reflect transaction prices in the reference countries and its perception as a price reduction and cost containment method, rather than an efficient resource allocation tool [4, 5, 7-9]. A further shortcoming is that ERP may lead to cross-country spillover effects such as launch delays with concomitant implications for access [7, 8, 10-13]. Price convergence, towards the basket's average, median or lowest price (depending on country stipulations) is observed as a result of ERP, while price instability can also be triggered as 
price fluctuations in one country may generate greater price fluctuations in another $[4,5,8,9,14]$.

Elsewhere, it has been shown that there is a lack of empirical evidence with clear methodological design and scarce evidence on the reasons why ERP impact varies within and across countries [15]. In this paper, we study the international implications of reference pricing and the extent to which these affect national policy objectives.

Based on the above, the objective of this paper is twofold: first, to study the implications of ERP systems at international level, particularly considering their likely spillover effects and access implications; and second to critically assess the quality and strength of evidence found in the literature against a set of pre-defined endpoints. To our knowledge, there is no other review up to this point examining the international implications of ERP and investigating whether policy-makers are considering these while designing an ERP system; and it is the first review, which appraises the quality of available evidence in order to establish whether the results of the potential impact of ERP across countries are robust or not.

\section{Conceptual background}

The justification for price intervention in pharmaceutical markets characterised by the entry of new and in-patent pharmaceutical products is provided by the predictions of monopoly pricing or monopolistic behaviour on the part of the innovator. As decision-makers face monopoly prices leading to less than optimal market coverage, the response would be to either impose a regulated price ceiling on entry prices of new products or to arrive at a suitable price based on an objective value assessment mechanism. Faced with the inability to identify a suitable or 'fair' entry price below the monopoly price and the lack of capability to assess the value of new pharmaceutical products based on objective criteria, a number of decision-makers rely on prices available in other settings. ERP is a pricing tool that has been used widely across countries, already since the late 1990s (e.g. in Greece, Italy, Portugal and Slovenia) [16]. When implementing a regulated price, it is hoped that this will contain the rate of growth of pharmaceutical costs, whilst at the same time help improve resource allocation decisions. As pharmaceutical suppliers typically launch products in settings where they can achieve the highest possible list prices, notably where explicit price regulation is not applied, the pool of reference countries to serve as a foundation for 'reference prices' to rely on is small. The launch of the same product in multiple settings, enables countries implementing ERP to update their price levels regularly and pursue price reductions at regular intervals based on the design characteristics of their ERP systems. Specifically, four key design elements lead to gradual price reduction and, consequently, cost minimisation: first, selection of reference countries for inclusion in country baskets, giving greater emphasis on low-price countries; second, selection of the reference price from the basket, emphasising the lowest in the basket or the average among the lowest quartile, quintile or decile of basket countries; third, the frequency of price revisions, in order to accelerate the process of price diminution; and, fourth, the use of 'favourable' exchange rates in order to arrive at even lower prices. Unavoidably, these design characteristics of ERP can deliver significant price reductions over time, and as significant cross-country referencing exists, a process of gradual price convergence towards the lowest is triggered.

From a game-theoretic perspective, manufacturers can predict the behaviour of countries that apply ERP, particularly as ERP design characteristics are embedded into legislation and, therefore, are publicly available. Consequently, manufacturers calibrate the sequence of market entry in such a way as to maximise gains from individual markets and minimise the effect of stepwise price reductions. The prospect of significant price diminution triggers a protective behaviour from manufacturers to delay the launch of products that are likely to be affected, or altogether not launching new products if such price diminution is likely to jeopardise prices in other markets. Manufacturers may adopt this strategy in order to minimise, or altogether eliminate, the spillover effects of cost minimisation from one setting into others. These spillover effects create deterministic pathways leading to a reduction in prices in all the countries using ERP, ultimately, triggering a race towards the lowest. As such, therefore, ERP has significant cross-border implications, which may transcend regional geographies, as cross-country referencing may not be limited to countries in the same geographical region, but can include countries from across geographies.

Taking the above into consideration and building on work undertaken previously on the subject [17], we created a framework in order to examine the international implications of ERP and the extent to which these implications are observed in the literature. In sum, the international implications include (a) the overall impact of spillover effects; (b) the potential impact of ERP on price stability; (c) the extent of price convergence across countries and (d) the extent of launch sequencing and launch delays. Table 1 summarises these endpoints and the issues generated by them.

\section{Methods}

The evidence informing this paper comes from a systematic literature review, which was carried out in accordance with the CRD guidelines for systematic reviews [18]. This was complemented by targeted primary data collection to better 
Table 1 Endpoints on the impact of ERP at international level Source: The authors

\begin{tabular}{|c|c|c|}
\hline Endpoints & Definition & Issues \\
\hline Spillover effects & $\begin{array}{l}\text { Assesses the effects expected to a certain extent by ERP, } \\
\text { which can prove problematic for the achievement of } \\
\text { national government policy objectives, e.g. spillover } \\
\text { effects. Spillover effects are a deterministic pathway } \\
\text { through which the basket of countries is selected based on } \\
\text { lowest price criteria }\end{array}$ & Impact of spillover effects \\
\hline Price stability & $\begin{array}{l}\text { Assesses the potential of ERP to help stabilise pharmaceuti- } \\
\text { cal prices so that random fluctuations caused by, among } \\
\text { others, unrelated events such as currency fluctuations, are } \\
\text { prevented }\end{array}$ & $\begin{array}{l}\text { ERP has the ability to promote price stability across countries } \\
\text { Price stability depends on ERP design } \\
\text { Price stability depends on market characteristics }\end{array}$ \\
\hline Price convergence & $\begin{array}{l}\text { Examines whether ERP leads to price convergence (and } \\
\text { whether this is upward or downward) or price divergence }\end{array}$ & $\begin{array}{l}\text { ERP leads to price convergence across countries } \\
\text { Type of price convergence (upward or downward) depends on } \\
\text { ERP design } \\
\text { Price convergence depends on exogenous factors other than } \\
\text { ERP }\end{array}$ \\
\hline Launch delays & $\begin{array}{l}\text { Examines whether there are delays in the launch of new } \\
\text { pharmaceuticals in third countries, exclusively due to ERP } \\
\text { rather than other regulatory measures, e.g. HTA, claw- } \\
\text { backs, rebates, among others }\end{array}$ & $\begin{array}{l}\text { Impact of ERP on pharmaceutical product launch } \\
\text { Impact of ERP on launch sequencing } \\
\text { Launch delays and launch sequencing may depend on factors } \\
\text { other than ERP }\end{array}$ \\
\hline
\end{tabular}

understand whether policy-makers take into consideration the international implications of ERP during its design.

\section{Systematic literature review}

\section{Data sources}

Evidence was collected according to a set of pre-defined endpoints based on the framework outlined in Table 1. There were no country-specific restrictions imposed on our search to ensure that evidence from a wide geographical range was collected. The study period for inclusion of relevant published studies was from January 2000 to December 2016. The start-date coincides with the period many countries started to implement ERP $[2,11,13,16]$.

To ensure the identification of all relevant information both peer-reviewed and grey literature were examined and included. Seven databases were searched [the Web of Science (WoS), CINAHL, EconLit, Medline, ProQuest, the Cochrane Library and Scopus] using the following keywords: "Pharmaceutical Price Regulation" OR "Pharmaceutical Regulation" OR "Cost Containment" OR "Pharmaceutical Pricing" OR "External Reference Pricing" OR "External Price Referencing" OR "International Price Comparisons" OR "International Reference Pricing" OR "International Price Referencing" AND drug OR drugs OR medicine OR medicines OR pharmaceutical OR pharmaceuticals. In addition to the systematic review and grey literature, a targeted search of the WHO, the WHO Collaborating Centre for Pharmaceutical Pricing and Reimbursement PoliciesGesundheit Österreich (WHOCC-GOEG), the OECD online databases and the European Commission was carried out to ensure that no relevant reports were omitted. The keywords used to search these databases were "External Reference Pricing" OR "External Price Referencing" OR "International Reference Pricing" OR "International Price Referencing". Relevant information was recorded and combined with the results of the systematic literature review.

\section{Study selection and data extraction}

The following stages were followed to select studies and extract data in adherence with the CRD guidelines: first, search results were filtered based on title and abstract relevance. Evidence from grey literature was also included in the systematic literature review in order to ensure that all relevant studies were considered. Studies with relevant titles were downloaded for further examination. The main body of these studies was then assessed for relevance against the inclusion criterion, notably, "mention of external price referencing and its impact across countries" at least in one of the selected endpoints in order to give a final set of potentially relevant studies. The number of documents presenting evidence on each endpoint was noted. Where one study presented evidence on more than one endpoint, this was recorded separately each time. An excel spreadsheet was used to extract the relevant information on each endpoint from the final set of studies included in this study. The spreadsheet comprised study titles in rows versus the endpoints in columns, with important information from the extracted texts. Where the search yielded studies, which were the product of a systematic literature review, they were 
only included in our analysis if the endpoints considered were different from those set out in this study, in order to gather as much information as possible whilst at the same time avoiding any possible bias. The same criteria in terms of timeline, language, keywords, title and abstract relevance were applied for both peer-reviewed and grey literature.

\section{Evidence assessment}

We did not expect to identify experimental designs in the studies included in this review. We, therefore, departed from the paradigm of assessing risk of bias in experimental studies used for healthcare interventions, such as randomised controlled trials, and assessed the quality of designs used in policy studies, including policy interventions. Strong designs such as quasi-experimental designs (based on the hierarchy ranging from time-series with or without comparator group, pre-post with or without comparator group and post-only designs), are often used to assess the impact of policy interventions [19] and provide different degrees of robustness. We categorised the studies identified in this review into empirical and non-empirical. The former comprised any randomised and non-randomised controlled trials, studies using quasi-experimental designs and other quantitative analyses. The latter, included theoretical models, descriptive studies as well as other literature reviews. Where descriptive studies provided quantitative evidence for a particular study endpoint(s), the initial piece of evidence was identified to assess its study design and its quality. We recorded both the study design and study timeline in all identified studies: the type of study design would enable us to make inferences about the robustness of the evidence and the extent to which it could provide meaningful policy recommendations; and study timelines would enable us to make inferences about short- or long-term implications, considering the likely effects of ERP on a policy variable or endpoint of 3 years or less to be "short-term" in nature.

\section{Primary data collection}

Primary evidence was generated using a brief survey as a supplement to the evidence resulting from the systematic literature review. The aim was to understand whether key stakeholders in national competent authorities consider the international implications of ERP during its design. Respondents from national competent authorities, insurance organisations, academic institutions and the pharmaceutical industry were asked to provide evidence, and their personal opinion, on the international implications of ERP as summarised in Table 1. The input received would represent the personal perspective of the respondents and not that of their institutions. The survey was administered via email between January and July 2017 to key stakeholders from
21 countries that implemented some form of ERP during the study period (Belgium, Brazil, Bulgaria, Egypt, Estonia, France, Germany, Greece, Hungary, Italy, Jordan, Latvia, Poland, Portugal, Qatar, Romania, Russia, Slovakia, Slovenia, South Africa and Spain). The country selection was made taking into consideration countries across the world, which implement ERP either as a primary or supportive tool in price setting.

\section{Data synthesis}

Results of the review were presented in a narrative way under each endpoint to summarise our findings, based on the CRD guidelines complemented by the evidence from primary data collection where applicable. We used the framework on Table 1 and the issues that each endpoint raised, to summarise the evidence from the peer-review and grey literature. Separately, we endeavoured to discuss the quality of evidence in support of the endpoints in order to gauge whether the documented effects might have been over- or under-estimated. For this purpose, a simple-vote counting approach was used to determine the accumulated impact of ERP on each endpoint and issues identified for each endpoint.

Based on the above, a template synthesising the results of this study was created and was populated with the results of the review summarised in four dimensions: first, the direction of impact (i.e. positive or negative) that ERP was found to have on the identified endpoints; second, the quality of the empirical evidence considered under individual endpoints (classified as high, moderate, low and very low); third, the overall extent of evidence in terms of number of studies identified regardless of their quality (high, moderate, low, very low) and; fourth, whether the studied endpoints and issues have been studied over the short- or longterm. Table 3 contains the synthesis based on these four dimensions.

\section{Results}

\section{Systematic literature review}

Figure 1 shows the PRISMA flow diagram of the review process and the respective number of articles at each stage. The database search yielded 6875 peer-reviewed and grey literature studies. The results of the systematic literature search were then combined with the results from the targeted search. Following removal of duplicates, using the EndNote software, 3977 studies were screened based on relevant titles and abstracts. Of these, 3489 studies were peer-reviewed and 488 were grey literature. 507 studies were identified as potentially useful and read in full to assess for eligibility. 
Fig. 1 PRISMA flow diagram outlining search results from the systematic literature review on international implications of external reference pricing. Source: The authors

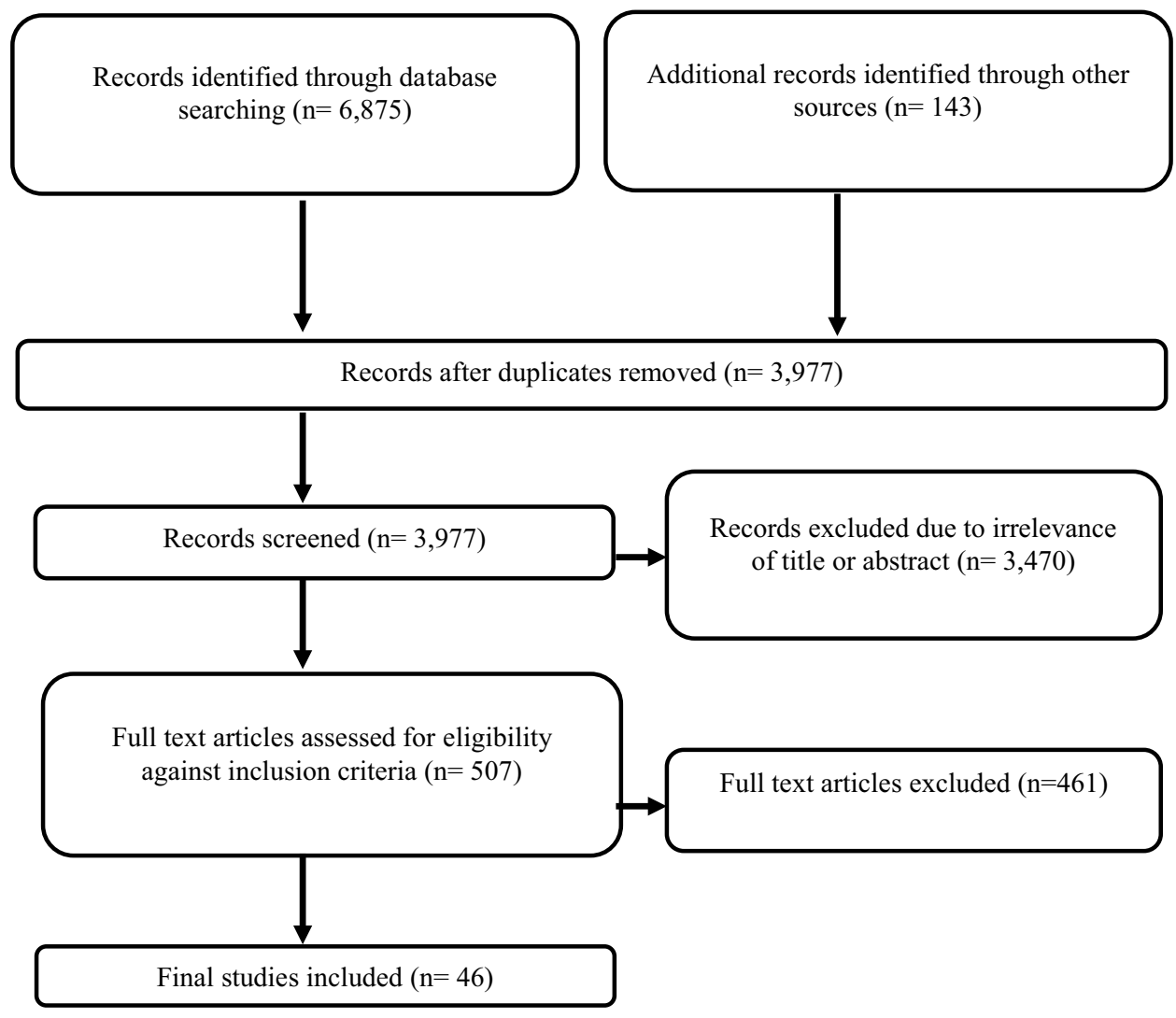

Studies were excluded if they were not relevant to ERP, focused on internal reference pricing, if full texts were not available and when they focused on the implications of ERP at a national level, which falls outside the scope of this study. The content of 46 studies was finally used to inform the findings. Four studies included in this systematic literature review were empirical studies (8.5\% of all included studies). Although the majority were a combination of descriptive studies, theoretical models or literature reviews, it has been observed that when examining the impact of ERP against the included endpoints, these studies used data collected by studies using a post-only design in order to capture the impact of ERP quantitatively. In such cases, the original data source was studied and recorded.

One systematic literature review [20] was extracted via our systematic literature search, which provided an overview of the process and potential issues of ERP systems in European countries including Iceland, Norway, and Switzerland. In this study, the authors examined the use of ERP and its impact on the prices of pharmaceuticals as well as the possible cross-country coordination issues in European countries. However, the scope and endpoints studied in this systematic literature review differ from the current analysis. The present search strategy was not limited to countries in the European region and had no country-specific limits. Therefore, we were able to include this study in our analysis. In addition, other non-systematic reviews [5, 21], which differ in scope, were included in this systematic literature review. A discussion of all available evidence by endpoint, along with issues identified for each endpoint, can be found in the sections that follow, while a summary is presented in Table 2 .

\section{Impact of spillover effects}

The term 'spillover' effects is typically used to describe the impact of ERP across borders. To achieve lower prices, ERP systems are designed based on a pre-defined basket, which usually contains low-price countries. Even though high-price countries might be included in the basket, most countries use the lowest price in the basket to calculate reference prices, which again will result in a reduced price in the country implementing ERP. In other words, spillover effects, which are embedded in ERP systems, follow deterministic pathways through which, prices are reduced across countries implementing ERP and are highly dependent on the construction of the basket and the way the reference price is calculated. Therefore, these effects are unavoidably experienced due to the nature of ERP itself.

We found that spillover effects indirectly cause price cuts in one country to be transferred to a third country [12]. A simulation model found that a $10 \%$ price cut in Romania (referenced by Greece and Bulgaria), would have caused 


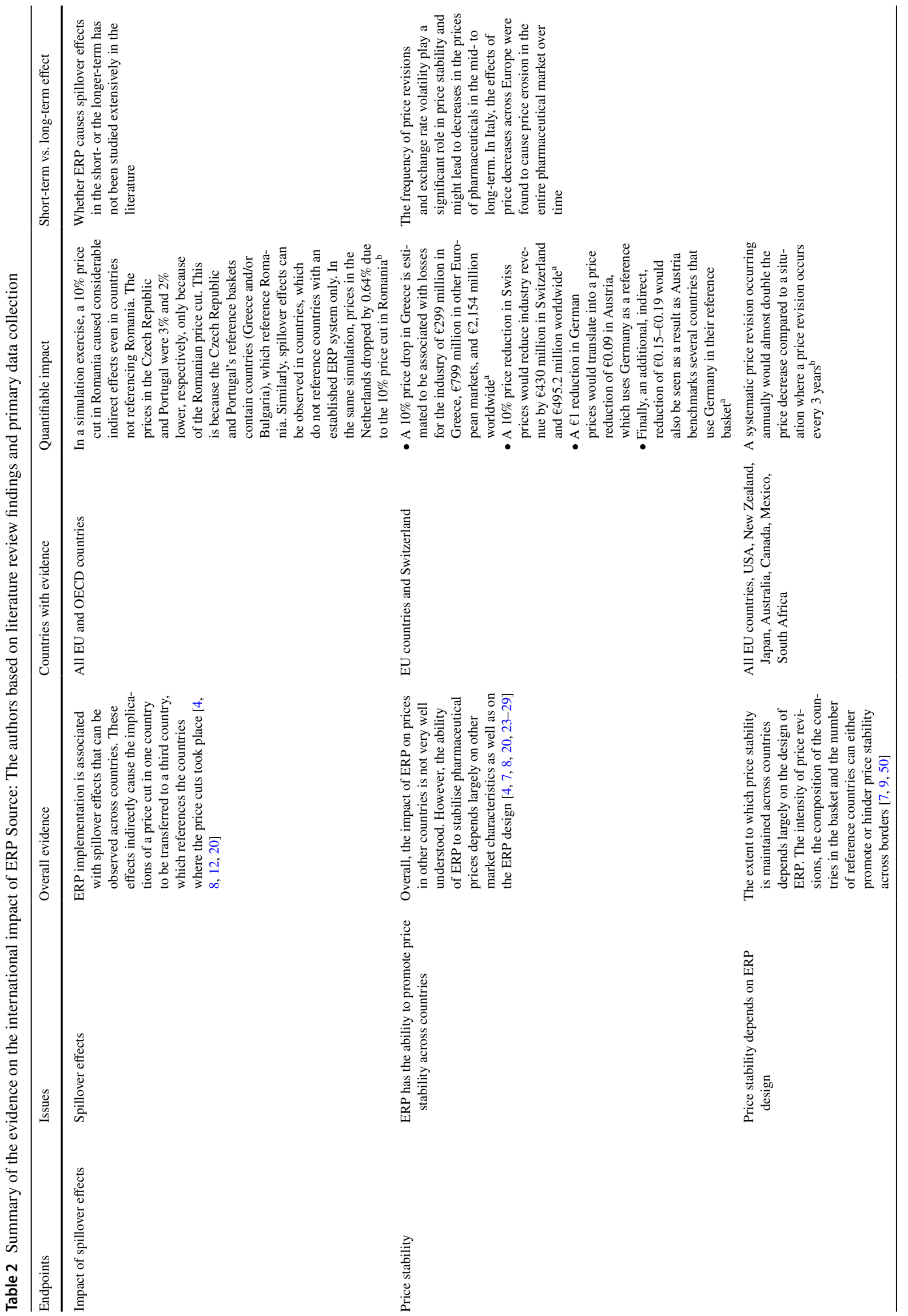




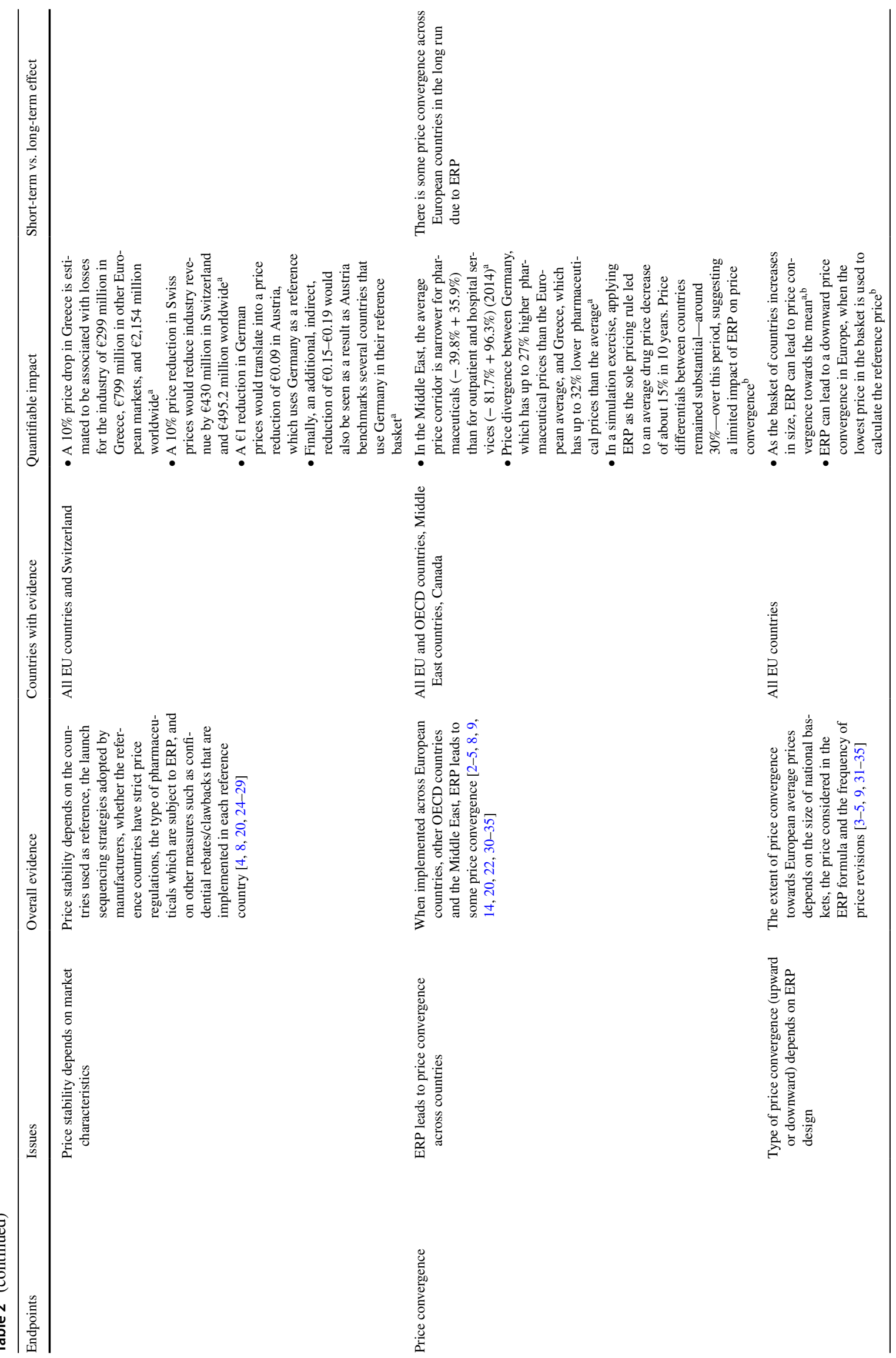




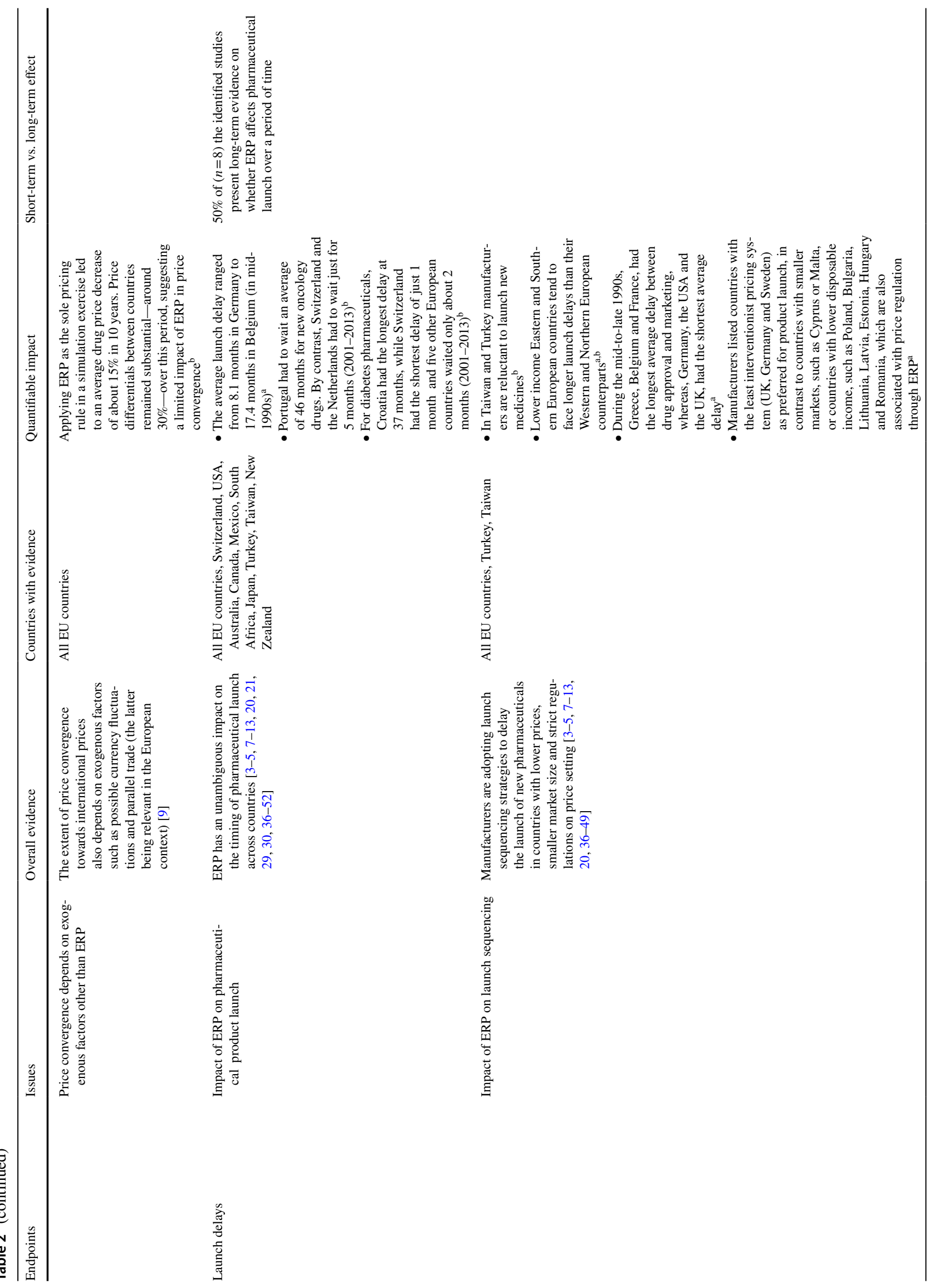




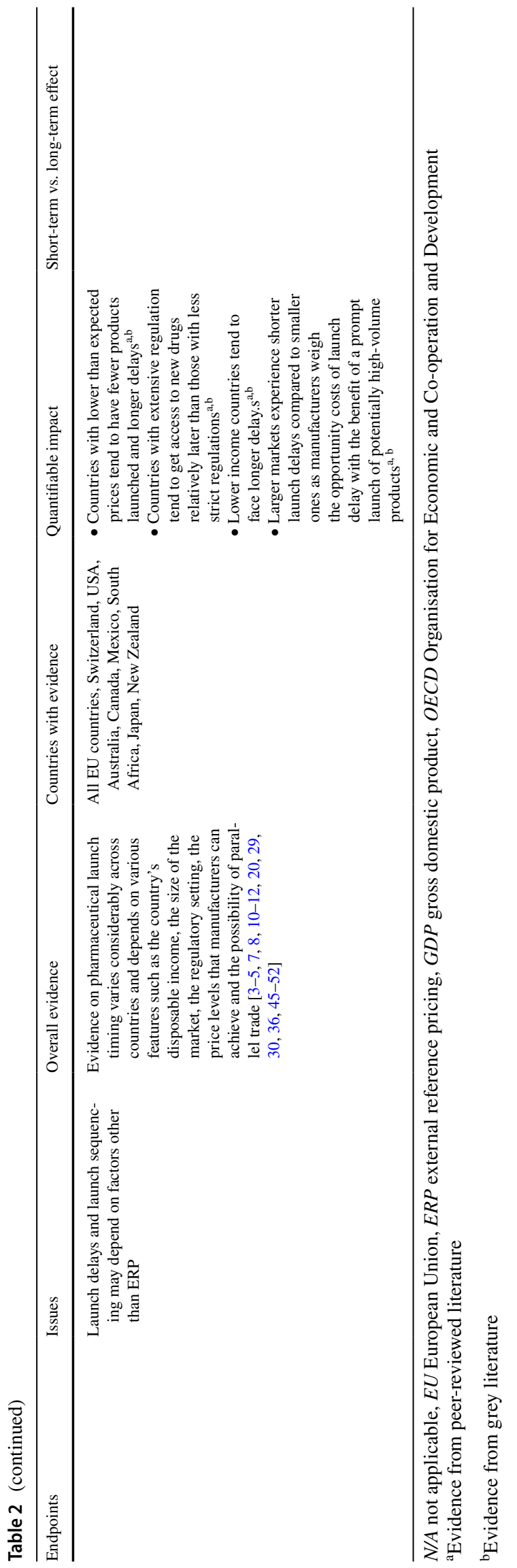

indirect spillover effects even in countries not using Romania in their basket. For instance, prices in the Czech Republic and Portugal would have been 3 and 2 per cent lower, respectively, because of the Romanian price cut. This is because the Czech Republic and Portugal's reference baskets contain countries (Greece and/or Bulgaria), which reference Romania [12]. Similarly, spillover effects can be observed in countries with mixed baskets (notably containing both countries using and not using ERP). In the same simulation, prices in the Netherlands dropped by $0.64 \%$ due to the $10 \%$ price cut in Romania. Of the countries included in the Dutch reference basket, only Belgium was using ERP (which, in turn, references Romania) and the price reduction in the Netherlands came from the effect of Romanian price reduction into Belgian prices [12].

Low price levels in one country can indirectly affect manufacturer pricing strategies elsewhere and potentially lead to increases in parallel trade $[8,20,22]$. Therefore, the spillover effects of low prices observed due to ERP systems across Europe can be a major concern for manufacturers, often leading to launch delays, promoting launch sequencing strategies and potentially result in limited access $[8,20]$. While the vast majority of the negative spillover effects discussed above relate to the phase when a product has been launched in many settings and, therefore, ample opportunities for cross-referencing and price diminution exist, in the initial phases, spillover effects can be positive: when only few countries experience product launch, typically, not affected by price controls, their prices are taken as reference in settings where price controls exist [8].

\section{Price stability}

Price stability centres on the potential of ERP to help stabilise pharmaceutical prices across countries, such that random fluctuations, for example due to the effect of different currencies, are prevented. The evidence from this endpoint addresses four specific issues: (1) whether ERP has the ability to promote price stability across countries; (2) whether price stability is realised in the short-, medium- and longterm; and examines possible factors that might affect the level of price stability, including (3) the ERP methodology or (4) other externalities.

In the literature ERP's ability to produce stable prices across countries and over time is not very well understood. This can be partly attributable to the substantial price differences observed among European countries implementing ERP [4].

The variation seen in ERP design across countries may indirectly affect price stability. Countries not only vary in the composition and size of their reference basket, but they also tend to employ different calculation methods to determine the reference price [23]. The apparent trend is 
for lower-price countries to be used as a reference, with the reference price deriving as a function of the lowest third or quartile in the selected basket. In addition, the use and frequency of price revisions, exchange rate volatility and the tendency of country baskets to revert towards the lowest price, can significantly sabotage price stability. The aforementioned features of ERP may exert a downward pressure on pharmaceutical prices in the mid- to long-term in a particular country and lead to cross-border knock-on effects [7]. In particular, the frequency of price revision is an important driver of price changes over time when applying ERP. It has been estimated that when systematic price revisions take place every year, the price decrease seen is almost double than the one seen when price revisions take place only every three years [9]. Thus, revising the intensity of price revisions in all countries will affect those with long periodicity, as increasing the revision frequency will contribute to decreasing overall pharmaceutical prices. This price decrease will further impact the prices in countries with high frequency of revision because of the referencing system, leading to unstable prices across countries [9]. Other factors related to ERP design, such as differing approaches used to tackle exchange rate fluctuations within the basket, the size of the basket, the ERP formula used and the different pricing policies implemented by the reference countries in the basket may also have an effect on price stability, however evidence on this in the literature is lacking.

With regards to external factors that could potentially affect price stability due to frequent price changes, ERP (a) places greater pressure on countries that are referenced by others to keep prices high, (b) when early market entry is preferred for new products or (c) when it is used to support the national pharmaceutical industry. This is due to the tendency pharmaceutical manufacturers have to set high entry prices for new products in countries without strict regulations, making these prices indicative for other countries that use ERP as a way to regulate prices in their own markets [4]. If manufacturers accept a lower than they expect price in one country, it may not only undermine their future price in another country where the product has not yet been launched, but may also undermine revenue based on its current higher price in the first country, due to spillovers and parallel exports [8]. A study [20] has documented the potential spillover impact of ERP across countries in the case of a price reduction due to ERP in a single country implementing ERP: assuming all study countries re-reference Greek/Swiss prices, a $10 \%$ drop in the Greek price was accompanied by estimated losses for industry of €299 million in Greece, $€ 799$ million in other European countries, and €2,154 million worldwide, whereas a $10 \%$ price reduction in the Swiss price reduced industry revenue by $€ 430$ million in Switzerland and $€ 495.2$ million worldwide [20]. In a simulation exercise, when assessing the impact of a price reduction in
Germany on the drug prices in a number of European countries using ERP (i.e. Austria, Greece, Ireland, Italy, Luxembourg, The Netherlands and Portugal), it was found that a $€ 1$ reduction in German prices translated into a price reduction of $€ 0.09$ in Austria, which uses Germany as a reference. An additional, indirect, reduction of $€ 0.15-€ 0.19$ would also be seen as a result, as Austria benchmarks several countries that use Germany in their reference basket. Therefore, price changes in Germany may have a cross-border impact in countries referencing Germany [4]. In Italy, the effects of price decreases across Europe were found to cause price erosion in the entire pharmaceutical market over time [24-28]. It has been argued that the impact of other countries' prices on the launch prices in a given country varies according to the type of pharmaceutical product. Evidence from Europe shows that launch prices of innovative and highly efficacious products are positively correlated with the lowest price received in high-price countries but the launch prices of 'me too' products are positively correlated with the lowest price received in high-price EU countries only $[4,8]$. The practice of agreeing to confidential rebates can also have an external effect as countries using ERP can only reference non-transactional prices, resulting in "list-price inflation". Clawbacks have a similar effect as the price is effectively changed post-transaction, after the list price has affected the global price via ERP [29]. In conclusion, the fact that confidential list price discounts exist can influence the ability of ERP to stabilise prices across countries and can further limit its credibility as a pricing policy, in that it can only serve as a starting point in price negotiations.

\section{Price convergence}

This endpoint examines the potential consequences of ERP in terms of upward or downward price convergence or price divergence across those countries using ERP. One potentially predictable impact of ERP implementation across countries is some level of international price convergence or harmonisation, although evidence from the literature is contradictory [8]. Three issues were identified in this context: first, the overall ability of ERP to harmonise prices across countries; second, whether this ability is observed over the long-term; and finally, the factors affecting any price convergence trend, which can be upwards, downwards or towards the mean. This final point is further divided into two issues based on the influence of, both, the ERP methodology and other exogenous factors on price convergence observed.

Overall, some price convergence has been detected in certain European countries, Canada and other OECD countries, due to extensive use of ERP [8, 22, 30]. Evidence from 2014, which compared average and minimum prices to mean prices of innovative pharmaceuticals and non-pharmaceutical services in six Middle East countries, showed that 
ERP systems reduced the pharmaceutical price differentials between countries with different economic status, resulting in a narrower price corridor for innovative pharmaceuticals. The average price corridor for innovative pharmaceuticals ranged between $-39.8 \%$ and $+35.9 \%$ in the study countries; in contrast, non-pharmaceutical outpatient and hospital services, which were not subjected to ERP, resulted in a price corridor ranging between -81.7 and $+96.3 \%$ [14]. In a 2005 Eurostat study, which examined the prices of ten on-patent medicines in 15 Western European countries from 2007 to 2012 to assess levels of convergence of ex-factory prices, a price divergence between 2008 and 2012 was shown and is believed to have been driven by two countries, Germany, where pharmaceuticals were $27 \%$ more expensive than the average, and Greece, where pharmaceuticals were $32 \%$ cheaper than the average. All other European countries in the study had prices that were close to the average [20].

In the long run, although there appears to be some convergence, the contribution of ERP was shown to be small at best $[2,9]$. This was confirmed by simulation results, where ERP was assumed to be the sole price intervention mechanism, demonstrating an average drug price decrease of about $15 \%$ over 10 years. The price differentials between countries remained substantial—around 30\%—over these 10 years, suggesting a limited impact of ERP in price convergence.

Larger baskets and an increase in basket size over time are associated with some price convergence in European pharmaceutical prices [3-5, 31-35]. The degree of price convergence is also determined by the design of the ERP system, and, in particular, the ERP formula and the frequency of price revisions. In this context, a simulation exercise has led to the argument that ERP can lead to a downward price convergence in Europe when the lowest price in the country basket, rather than the average price, is used to calculate the reference price [9].

With regards to exogenous factors affecting price convergence when ERP is applied, it has been found that currency fluctuations in Europe and parallel trade can contribute to price convergence [9], although there may be other confounders contributing to this, such as different pricing policies implemented across countries [9]. However, the evidence synthesised in this section should be seen as being independent of other pricing schemes as these regulations could either be applied across the board or could have been used in a selective manner, i.e. for specific pharmaceutical products only.

\section{Launch delays}

This section examines the existence of delays in the launch of new pharmaceuticals in other countries solely as a result of ERP. Launch delays are usually calculated as the difference in months between marketing authorisation and the country-specific launch date $[7,11]$. Four issues were identified under this endpoint: first, the impact of ERP on pharmaceutical launch in general; second, whether ERP promotes launch sequencing; third, the broader circumstances under which launch delays and launch sequencing can occur; and, fourth, whether ERP affects product launch in the long run.

Throughout the identified literature, the relationship between ERP and launch delays is ambiguous as the extent of these delays varies across countries [3, 7, 11, 12, 21, 36]. Evidence shows that from 1994 to 1999, the three countries with the greatest number of launches were Sweden, Denmark and Germany, whereas the four countries with the fewest number of launches were Portugal, Italy, Greece, and Spain; the average launch delay, as defined above, ranged from 8.1 months in Germany to 17.4 months in Belgium $[11,21]$. The average delay for in-patent oncology pharmaceuticals was calculated for 2001-2013 using IMS data and a post-only design. Portugal had the largest launch delays and had to wait an average of 46 months after the launch of new oncology pharmaceuticals in other European markets. Switzerland and the Netherlands, on the other hand, waited just 5 months for the same products. For diabetes pharmaceuticals, Croatia had the longest delay at 37 months, while Switzerland had one of the shortest delays at just 1 month. Five other European countries with higher GDP, waited only about 2 months [12].

"Launch sequence strategy" is used by manufacturers as a strategy to delay or avoid launching new pharmaceuticals in countries with lower prices and/or low sales volume, particularly if these are small markets referenced by countries with larger markets [4, 5, 7-10, 20]. For instance, manufacturers may strategically delay the launch of a new product in a lower-price country if that country's prices will lower prices in higher-price countries as a result of the ERP spillovers [3, 11, 12, 36-40]. In Slovakia, the Ministry of Health allowed a $10 \%$ higher launch price than the average price of the three lowest-priced reference countries so pharmaceutical companies would not delay launching. By launching their new pharmaceuticals in Slovakia, manufacturers were able to price their drugs above the lowest price elsewhere in Europe, allowing room to launch their products before the price was established in other low-price countries as well as keep the Slovak price higher than elsewhere in Europe [41].

Evidence on the impact of ERP on launch sequencing strategies is available from a post hoc assessment of secondary data arising from relevant literature on time-to-market access and the price levels of innovative pharmaceuticals in $33 \mathrm{EU}$ countries. This assessment showed that in Belgium, companies systematically delayed dossier submission in order to avoid the Belgian price, which is typically not among the highest within the EU [20]. Furthermore, in market research reports for Taiwan [42, 43] and Turkey [44], 
regression-based forecasts expressed concerns that manufacturers might be reluctant to launch new medicines in these countries as they would be subjected to low prices immediately. Overall, it appears that countries having lower than expected prices tend to have fewer products launched and face longer launch delays [7, 11, 13, 45-49]. This observation is not without confounders and may also be related to longer bureaucratic processes required to reach price agreements with governments.

Pharmaceutical firms may also delay launching their products in a country due to the ERP policy itself, or in situations where they assume that the resulting price will be prohibitively low in a particular market. Evidence suggests that manufacturers are less willing to launch in countries where ERP is implemented due to the impact ERP has on price levels $[4,8,10,12,29,50]$ and are more likely to launch innovative pharmaceuticals in countries with more lax regulations, where there is freedom to set entry prices because of the concomitant effects on third countries' reference baskets $[4,5,7,8,10-12,30,45-49,51]$. During the mid-to-late 1990s, launch-price regulating countries (Greece, Belgium and France), had the longest average delay between drug approval and marketing, compared with non-price regulating countries (Germany, the USA and the UK), which had the shortest average delay [11]. A European Commission study showed that when manufacturers were asked about their preferences for launching a new product they listed countries with the least interventionist pricing system (i.e. UK, Germany, Sweden) as preferred for product launch purposes, in contrast to countries with smaller markets (e.g. Cyprus or Malta), or with lower disposable income (e.g. Poland, Bulgaria, Lithuania, Latvia, Estonia, Hungary and Romania), which are also associated with price regulation through ERP [7]. Overall, lower income Eastern and Southern European countries, which implement stricter price regulations, tend to face longer delays than their Western and Northern European counterparts with higher GDP per capita $[3,12,36]$. Evidence has shown that market size matters and larger markets experience shorter launch delays compared to smaller ones as manufacturers weigh the opportunity costs of launch delays with the benefit of a prompt launch in potentially high-volume markets. This dominates any incentive regulators have to delay the launch of high-volume products that could have a disproportionate budget impact [11].

With regards to the factors affecting launch delays when ERP is implemented, EU Member States seem to be more exposed to spillover effects than non-EU countries due to the existence of parallel trade among the former, the majority of which formally, or informally, implement ERP to determine pharmaceutical prices. The interdependence of European countries gives an additional incentive to manufacturers to launch new pharmaceuticals in high-price countries first and to delay launch, or even prevent launch entirely, in low-price countries [52]. Parallel trade effectively arbitrages price differences across countries and thus, has a similar effect to ERP in terms of compressing price differences and inducing strategic launch behaviour by firms [4, 7]. Therefore, even though there is evidence of strategic launching due to ERP, its impact on timely access in low price countries is unclear as other factors may contribute to this, including the likelihood of parallel trade [20].

\section{Evidence assessment}

As impact assessment studies in pharmaceutical policy have been found to be weak, often casting doubt on many of the conclusions drawn, we critically assessed the quality of evidence used in this systematic review by appraising the methodological design of the identified studies. Randomised control trials (RCTs) and studies with strong quasiexperimental designs (e.g. time-series with a comparison group), are considered to be well-controlled compared to before-after or post-only studies, which are considered to be weaker designs, often producing unreliable results [19]. None of the studies included in this paper was identified with an experimental design or a strong quasi-experimental design and most had weak quasi-experimental designs. Twelve studies presented evidence on the impact of ERP on price stability, including two peer-reviewed studies and ten studies from grey literature. Of these, two were descriptive, presenting different pharmaceutical pricing regulations as well as the modalities of ERP in European countries and its potential impact $[23,29]$ and one study developed simulation models to test several hypotheses about the effects of ERP [9]. Empirical evidence was collected by one study using a regression model [4] and by eight descriptive studies examining the promotion of price stability as a result of ERP systems across European and OECD countries, referencing other studies employing regression analysis or a post-only design [7, 8, 20, 24-28]. Three out of the 12 studies provided evidence on the potential long-term effect of ERP on price stability [7-9]. Fifteen studies were identified presenting evidence on the impact of ERP on price convergence. Of these, 8 were peer-reviewed and 7 were derived from grey literature. Five of the 15 studies were descriptive, discussing the current healthcare situation of the study countries [31-35], 2 used a simulation exercise to assess the price dynamics through ERP-based systems [2,9] and one developed a theoretical model to study whether pharmaceutical firms are incentivised to launch their products in countries implementing ERP [3]. Empirical evidence was extracted from 7 studies, of which 2 used data through a post-only design, collected either from competent authorities or the Eurostat database $[8,20]$ and 5 studies analysed whether ERP leads to price convergence using either regression $[4,5,14,30]$ 
or difference-in-differences analysis [22]. Four out of the 15 studies provided long-term evidence by studying the effect of ERP on price convergence over a period of more than 5 years $[8,9,20,22]$. Four studies provided a general description of the type of cross-country spillover effects caused by ERP systems and the process by which these might be triggered. Two of these were peer-reviewed. Three studies provided descriptive evidence drawn from Europe [8, 12, 20], whereas one descriptive study provided quantitative evidence with a post-only design using data from IMS and from competent authorities, when studying potential spillover effects of ERP [12]. The final study was empirical using a regression model to examine the potential impact of ERP on pharmaceutical prices [4]. Thirty-one studies looking at the impact of ERP on the launch of new pharmaceuticals were identified in the literature. Of these, 14 were peer-reviewed and 17 were extracted from grey literature. Fourteen studies were descriptive [5, 38, 39-51], eight were both descriptive and empirical in nature describing ERP systems and their modalities using post-only data from readily available sources and from IMS [7, 8, 10, 12, 20, 29, 39, 52] and, additionally, two descriptive studies referenced an empirical study with a regression model when studying launch delays in other countries $[13,21]$. Three studies built a theoretical model to test how firms respond to the launch of their pharmaceuticals in countries implementing ERP $[3,36,37]$ and one study performed a simulation exercise [9]. Finally, three studies were purely empirical using a regression model to test whether price regulation affects the launch of a pharmaceutical in specific countries $[4,11,30]$. From the 31 studies included in this endpoint, 6 provided long-term evidence on the impact of ERP on launch delays [7, 9-12, 21]. Table 3 presents the overall direction of evidence and quality of existing evidence found in the available literature on the impact of ERP across countries.

\section{Primary data collection}

Of the 21 countries that formed part of the primary data collection process, 17 countries (Belgium, Brazil, Bulgaria, Egypt, Spain, Estonia, Greece, Hungary, Italy, Latvia, Poland, Qatar, Romania, Russia, Slovenia, South Africa and Jordan) and a total of 19 stakeholders (2 each from Hungary and Brazil) responded to the survey questions providing feedback on whether the international implications of ERP are taken into account during the design phase of ERP. In Egypt, Estonia, Hungary, Latvia, Qatar, Russia, Slovenia and South Africa, the international implications of ERP are not considered during its design [53]. Similarly, in Romania, the likely effect from parallel trade, arising from price differences between Romania and other countries, is not considered in the ERP design, even though there is extensive evidence of this phenomenon in the country [53]. There was limited information from Spain, in terms of the basis on which the design of ERP was informed; therefore, we are unable to comment on whether or not the international implications of ERP are considered [53] by decision-makers in these cases. In Greece, Jordan and Slovakia the international effects of ERP are considered, mainly because all are used as reference countries and decision-makers are aware of the international spillover effects of ERP, particularly those relating to parallel trade [53]. Specifically, in Greece and Slovakia parallel trade often results in drug shortages, which is why in the former case, the government has on several occasion issued temporary export bans to discourage products from leaving the country [53]. In Belgium, parallel trade is consistently highlighted as a problem by the industry and is stated as a reason why they cannot allow lower list prices [53]. In Bulgaria, parallel trade is considered in the design of ERP and the focus is mostly on parallel exports, due to the increased likelihood of shortages [53]. In Poland, the ERP system is no longer used explicitly to inform prices. However, spillover effects and parallel trade are considered when manufacturers maintain a higher official price, which is publically available [53]. In Brazil, the international implications considered during the ERP design are the growth of parallel trade after the initiation of ERP and spillover effects caused by positive restrictive formularies and guidelines [53].

\section{Discussion and policy implications}

The evidence identified on the impact of ERP across countries showed that ERP may lead to price convergence, price instability and launch delays and has significant spillover effects. Table 2 summarises the available evidence from across the body of identified literature.

With regards to the general cross-country spillover effects and the link to ERP, spillover effects have unintended consequences in countries where ERP is the dominant method in price setting. The impact of spillover effects due to the nature of ERP has been documented, showing that ERP unavoidably follows a deterministic pathway in which prices can decline across countries if one country applies price cuts or if launch prices in some settings are lower than in others. Primary data collection suggested that only $47 \%$ of countries consider the international implications of ERP when designing their ERP system. By considering these effects during the design process, many countries could have prevented at least some of the undesirable consequences of this pricing policy.

Evidence on whether ERP contributes to price stability is complex to interpret, as it may be linked to other parameters operating in tandem. A limited number of studies concluded that ERP most likely leads to price instability across countries, as price fluctuations in one 
Table 3 Evidence synthesis on the international impact of ERP Source: Synthesis by the authors

\begin{tabular}{|c|c|c|c|c|c|}
\hline Study endpoints & $\begin{array}{l}\text { Issues identified within } \\
\text { endpoints }\end{array}$ & $\begin{array}{l}\text { Impact of ERP } \\
\text { Positive }(+) \text { Negative } \\
(-) \text { or Ambiguous } \\
(+/-)^{\mathrm{a}}\end{array}$ & $\begin{array}{l}\text { Quality of empiri- } \\
\text { cal evidence on the } \\
\text { impact of ERP (where } \\
\text { applicable) }\end{array}$ & $\begin{array}{l}\text { Overall extent of } \\
\text { evidence on the impact } \\
\text { of ERP }\end{array}$ & $\begin{array}{l}\text { Duration evidence } \\
\text { applies to: short-term } \\
\text { (S) or long-term }(\mathrm{L})^{\mathrm{d}}\end{array}$ \\
\hline Spillover effects & $\begin{array}{l}\text { Impact of spillover } \\
\text { effects }\end{array}$ & + & Very low & Very low & $\mathrm{S}$ \\
\hline \multirow[t]{3}{*}{ Price stability } & $\begin{array}{l}\text { ERP has the ability to } \\
\text { promote price stabil- } \\
\text { ity across countries }\end{array}$ & - & Very low & Low & $\mathrm{L}$ \\
\hline & $\begin{array}{l}\text { Price stability depends } \\
\text { on ERP design }\end{array}$ & $+/-$ & Very low & Very low & \\
\hline & $\begin{array}{l}\text { Price stability depends } \\
\text { on market character- } \\
\text { istics }\end{array}$ & $+/-$ & Very low & Low & \\
\hline \multirow[t]{3}{*}{ Price convergence } & $\begin{array}{l}\text { ERP leads to price } \\
\text { convergence across } \\
\text { countries }\end{array}$ & $+/-$ & Low & Moderate & $\mathrm{S}$ \\
\hline & $\begin{array}{l}\text { Type of price conver- } \\
\text { gence depends on } \\
\text { ERP design }\end{array}$ & $+/-$ & Very low & Low & \\
\hline & $\begin{array}{l}\text { Price convergence } \\
\text { depends on exog- } \\
\text { enous factors other } \\
\text { than ERP }\end{array}$ & $+/-$ & Very low & Very low & \\
\hline \multirow[t]{3}{*}{ Launch delays } & $\begin{array}{l}\text { Impact of ERP on phar- } \\
\text { maceutical product } \\
\text { launch }\end{array}$ & $+/-$ & Low & High & $\mathrm{S} / \mathrm{L}$ \\
\hline & $\begin{array}{l}\text { Impact of ERP on } \\
\text { launch sequencing }\end{array}$ & $+/-$ & Very low & High & \\
\hline & $\begin{array}{l}\text { Launch delays depend } \\
\text { on factors other than } \\
\text { ERP }\end{array}$ & $+/-$ & Low & Moderate & \\
\hline Overall & & $+/-$ & Very low & Low & Mainly S \\
\hline
\end{tabular}

aThe "+" sign indicates that ERP contributes to achieving the stated goal(s) whereas the "-" sign indicates that it does not contribute to achieving the stated goal(s). The sign "+/-"is used where the impact of ERP on the relevant endpoint/issue is ambiguous. This is generally observed when the impact of ERP depends on other factors, such as the modalities of ERP methodology or other exogenous factors. A simple-vote counting methodology was used by counting the number of the identified studies providing positive evidence and the number of those providing negative evidence

${ }^{b}$ The overall quality of the identified empirical evidence has been classified as high, moderate, low, very low and not available. Only studies examining each endpoint/issue empirically were considered. Quasi-experimental designs had a 'high' classification, post-only designs were classified as 'very low', whereas studies performing a regression analysis had a 'moderate' classification. Under each endpoint/issue, when different types of empirical studies were considered, the quality of evidence was then assessed according to the majority

${ }^{c}$ Represents an overall estimation of the extent of evidence on whether adequate evidence was identified in terms of number of studies regardless of their quality. A grading system is used here, denoted by the number of studies included under each endpoint and the identified key issues; if the evidence presented under each endpoint/issue was derived from 22 or more studies, the extent of this evidence was classified as high; from 15 to 21 as moderate; from eight to 14 as low; from one to seven studies as very low; and zero studies as not available

${ }^{\mathrm{d}}$ Refers to the timeline covered by the relevant evidence and whether this is predominantly short- ("S") or long-term ("L"). If both, then "S/L" is used

country trigger price fluctuations elsewhere, leading to higher prices and lower availability of medicines. One could argue that as ERP is a tool used to regulate pharmaceutical prices across countries, its potential to stabilise pharmaceutical prices across countries should be high. However, evidence shows that prices actually fluctuate due to numerous factors, including market characteristics, the variable designs in ERP systems, currency fluctuations, manufacturers' incentives, type of pharmaceutical products (innovative or me-too) and specific country-based regulations, which contribute to price instability across countries. Price convergence is also likely to occur when ERP is implemented across countries at least in the shortterm. The evidence presented in this study showed that 
ERP systems are expected to reduce pricing differentials, but there are examples where price divergence is also observed.

Evidence on launch delays varies considerably across countries. Our findings suggest that launch delays depend on various determinants such as country disposable income, market size, the overall regulatory environment and manufacturer pricing and entry strategies. One could argue that other regulatory interventions used in price setting and/or reimbursement can lead to launch delays. Health technology assessment (HTA) is one such intervention and, depending on the model pursued (rapid review vs. full deliberative model), it can lead to moderate to significant delays in access [54-56]. Despite these, the outcome of HTA is in the vast majority of cases positive or positive with restrictions [57, 58]; ERP by contrast, can result in a long delay and, in some cases, permanent non-entry, if price levels in the target country are expected to be low enough as to pose a threat to manufacturers' global pricing and market entry strategies.

As shown extensively throughout the literature, launch sequencing and delays have international consequences by limiting the access to and availability of pharmaceuticals in smaller countries, in those with low price levels and those with stricter price regulations or those who must wait for other countries to make a decision on both reimbursement and price. Therefore, although ERP aims to deliver better control of prices and faster price erosion, it might also lead to unwanted effects, such as triggering increases in list prices by manufacturers in order to avoid both parallel trade and any potential impact on revenues [20].

Findings from both this study and another, looking at the impact of ERP within countries [15], highlight a bidirectional relationship between the impact of ERP within and across countries. Potential price convergence caused by ERP reinforces narrow price ranges across countries, which can be unfavourable for low-income countries facing price increases generally towards the basket average. As such, it may hinder availability and affordability of pharmaceuticals within a country. At the same time, launch delays caused by lower price levels resulting from ERP in third countries would result in non-availability of pharmaceuticals.

Both the impact of ERP at national and international levels depend largely on the design of the ERP system and other exogenous factors. It has been explicitly stated in the literature that country-specific characteristics, such as market size, health system regulations, other pricing mechanisms employed, and the nature and design of the ERP system play a pivotal role on the impact ERP has both within and across countries. Income levels, proxied by GDP per capita, have also been shown to have an indirect relationship with ERP impact, by influencing the extent of launch delays.
Specifically, GDP per capita levels are in principle inversely related to launch delays.

ERP has been criticised for "path dependence", suggesting that the features of the ERP system shape the overall impact it has. Consequently, by calibrating certain features of ERP its overall function can be optimised. For instance, the formula used to calculate prices within the ERP system needs to be set more cautiously: using an average-based formula could reduce launch delays, promote availability and, ultimately, contribute to price stability across countries. Countries in the basket (and their corresponding currencies), the size of the basket, the timing of price revisions and the exchange rate used for this purpose, should be selected carefully so that unwanted effects, such as exchange rate volatility, which can cause price instability across countries, can be minimised. Consequently, and based on the evidence from the literature, by modifying certain elements of the overall ERP system design to revise prices at less frequent intervals (e.g. annually or every 5 years, rather than every quarter or even twice annually), decreasing the basket size and avoiding referencing countries with intense price regulations, spillover effects experienced due to ERP could be minimised. These suggestions are broadly in line with a set of 14 principles [59] recommended for the development of an 'ideal' ERP system which are discussed in more detail in another paper in this series, which outlines the variation seen in the implementation of ERP systems in a number of countries [16].

Despite the relative wealth of evidence found on the impact of ERP across a country's borders, we conclude that any such impact remains ambiguous due to the limited number of empirical studies and their relatively weak research design. Specifically, we can conclude that the strength and the quality of evidence on the impact of ERP on spillover effects is very low. The identified empirical evidence regarding the ability of ERP to result in price stability and price convergence across countries uses, in most part, weak methodological designs, resulting in both low quality of evidence and a lack of quantifiable evidence. The strength of evidence on the impact of ERP on launch delays and launch sequencing is relatively high compared to other endpoints. However, the quality of evidence on this endpoint is still relatively weak, arising from a post-only analysis and three regression models. Few examples exist in the literature showing long-term measureable impact. Therefore, any interpretation of results stemming from the literature on "launch delays" should be interpreted with caution. A better understanding is needed of the reasons behind pharmaceutical launch delays, and whether these are experienced in the presence of ERP over time [13].

Overall, the evidence presented in this paper is classified as poor in terms of quality, as it comprised only a limited volume of empirical evidence with acceptable (e.g. 
quasi-experimental) designs that would lead to robust conclusions. Some of the evidence reviewed was based on qualitative analysis of survey data or regression analyses of observational data, where bias and/or potential confounders could not be controlled. In addition, as the majority of the evidence considered is short-term in nature, no major conclusions can be drawn about the longer-term implications of ERP. A key finding is that the majority of studies (67\%) looking into the international implications of ERP comes from grey literature, which predominately comes from official reports of the European Union, the WHO and the OECD. Although we cannot justify fully why evidence on ERP derives mainly from grey literature, and, specifically, international organisations, we surmise that the latter have a keen interest in the impact of pricing policies, their effectiveness and wider implications.

Robust research using empirical evidence with strong methodological design and a longer time horizon is urgently needed to understand and, eventually, interpret the drivers influencing the impact of ERP across countries. Nevertheless, this is becoming cumbersome, as ERP is increasingly used as a starting point of negotiations or in combination with other pricing policies, which suggests that there is a whole host of parameters and confounders that need to be accounted for in order to evaluate its performance. One of them is the increased use of confidential discounting, which renders ERP largely ineffective as a price control tool, as list prices for most new products are fictitious as they do not incorporate discounts or other arrangements negotiated between competent authorities and manufacturers in reference countries.

\section{Limitations}

A number of limitations were encountered, mainly due to limitations experienced when performing the systematic literature review. First, the literature was scanned using online databases, where the results were limited to English. As a result, relevant studies published in a language other than English were excluded. Second, as pharmaceutical pricing policies are constantly updated and undergoing change, the evidence presented in this systematic literature review may not reflect the policy landscape in the future. However, this study provides a benchmark at a specific point in time and could inform future comparisons. Third, a significant proportion of the studies reviewed came from grey literature, were mostly descriptive in nature, had weak methodological designs and, consequently, were perceived as low quality. However, even weak designs, such as pre-post analysis, can provide meaningful input in circumstances where evidence is altogether missing. Finally, while we performed an assessment of the quality of evidence of the studies that met the inclusion criteria, we did not follow or use formal critical appraisal and assessment tools for systematic reviews to assess their methodological quality, but instead, focused on the type of design (experimental, non- or quasi-experimental) that was implemented. This does not necessarily reduce the validity of the results obtained and was chosen in recognition of the fact that none of the policy studies identified had an experimental design.

\section{Conclusion}

ERP appears to be associated with international implications, including spillover effects, price instability, price convergence and launch delays; these have been widely observed across countries. However, these effects cannot be solely attributed to or caused by ERP per se and there may be other factors at play; market size and income levels (in terms of GDP per capita) of a country, exchange rate fluctuations as well as other supply-side regulations can either trigger one or more of these effects or, indeed, reduce their impact. Nevertheless, the nature of ERP facilitates these unintended consequences and directly links them to it. Despite these cross-country implications being well known to decisionmakers, they are not necessarily considered when the design of ERP systems takes place.

Given that the evidence we found in the currently available literature was mostly weak in terms of quality and derived mainly from grey literature, the above observations should be interpreted with caution. Importantly, there seems to be a dual unmet need: the first, relates to what constitutes an optimal ERP system design, so that its impact across countries would be at least neutral; and, the second, relates to the robust quantification of its impact at international level, including practices countries have used to address spillover effects.

Acknowledgements We are grateful to Mackenzie Mills, Nicola Boekstein, Olina Efythimiadou, Erica Visintin, David Taylor and two anonymous referees for valuable comments and suggestions. We would also like to thank Ibrahim Abbadi, Jakub Adamski, Daoud AlBadriyeh, Diāna Arāja, Anya Bazhenova, Tatyana Benisheva, Irina Cleemput, Nevine Elnahass, Jaime Espin, Zoltán Kalo, Chara Kani, Gabor Lengyel, Vlad Mixich, Anban Pillay, Valentina Rupel, Marisa Santos, Tomas Tesar, Joice Valentim and Kärt Veliste for their personal input. This paper was undertaken in the context of the LSE HealthMedical Technology Research Group Pharmaceutical Regulation programme. All outstanding errors remain our own.

\section{References}

1. World Health Organization: WHO Guideline on Country Pharmaceutical Pricing Policies. World Health Organization, Geneva (2013) 
2. Espin, J., Rovira, J., Ewen, M., Laing, R.: Mapping external reference pricing practices for medicines. Health Action International and the Andalusian School of Public Health (2014)

3. Houy, N., Jelovac, I.: Drug approval decision times, international reference pricing and strategic launches of new drugs. International Reference Pricing and Strategic Launches of New Drugs (2014)

4. Leopold, C., Mantel-Teeuwisse, A.K., Seyfang, L., Vogler, S., de Joncheere, K., Laing, R.O., Leufkens, H.: Impact of external price referencing on medicine prices-a price comparison among 14 European countries. South. Med. Rev. 5(2), 34-41 (2012)

5. Leopold, C., Vogler, S., Mantel-Teeuwisse, A.K., de Joncheere, K., Leufkens, H.G.M., Laing, R.: Differences in external price referencing in Europe-a descriptive overview. Health Policy 104(1), 50-60 (2012). https://doi.org/10.1016/j.healthpol.2011.09.008

6. World Health Organization: Regional Office for Europe: Access to new medicines in Europe: technical review of policy initiatives and opportunities for collaboration and research (2015). http:// www.euro.who.int/_data/assets/pdf_file/0008/306179/Acces s-new-medicines-TR-PIO-collaboration-research.pdf?ua $=1$

7. Kanavos, P., Nicod, E., Espin, J., Van Den Aardweg, S.: Shortand long-term effects of value-based pricing vs. external price referencing. Eminet. LSE (2010)

8. OECD: Pharmaceutical pricing policies in a global market. Organisation for economic co-operation and development (OECD), Paris (2008)

9. Toumi, M.: External reference pricing of medicinal products: simulation-based considerations for cross-country coordination. European Commission, Brussels. https://ec.europa.eu/health/sites /health/files/systems_performance_assessment/docs/erp_reimb ursement_medicinal_products_en.pdf (2014). Accessed 25 Sept 2015

10. European Commission: Study on enhanced cross-country coordination in the area of pharmaceutical pricing. https://ec.europa.eu/ health/sites/health/files/systems_performance_assessment/docs/ pharmaproductpricing_frep_en.pdf (2015). Accessed 8 June 2016

11. Danzon, P.M., Wang, Y.R., Wang, L.: The impact of price regulation on the launch delay of new drugs - evidence from twenty-five major markets in the 1990s. Health Econ. 14(3), 269-292 (2005). https://doi.org/10.1002/hec.931

12. Europe Economics: External Reference Pricing. http://www.europ e-economics.com/publications/external_reference_pricing_-_final _report.pdf (2013). Accessed 25 Sept 2015

13. Espin, J., Rovira, J.: Analysis of differences and commonalities in pricing and reimbursement systems in Europe. Brussels: DG Enterprise and Industry of the European Commission 100 (2007)

14. Kaló, Z., Akhras, K.S., Voko, Z., Kanavos, P.: The implications of external price referencing of pharmaceuticals in Middle East countries. Expert. Rev. Pharmacoecon. Outcomes Res. (2015). https://doi.org/10.1586/14737167.2016.1136792

15. Kanavos, P., Gill, J., Efthymiadou, A., Fontrier, A.-M.: Does external reference pricing deliver what it promises? Evidence on its impact: in review (2019)

16. Gill, J., Kanavos, P., Kyriopoulos, D., Fontrier, A-M.: Variation in external reference pricing implementation-does it matter for public policy? in review (2019)

17. Kanavos, P., Fontrier, A.M., Gill, J., Efthymiadou, O., Boekstein, $\mathrm{N}$. The impact of external reference pricing within and across countries. LSE (2017). https://doi.org/10.21953/lse.m0bluqcv10 g6

18. Centre for Reviews and Dissemination (CRD): Systematic Reviews-CRD's guidance for undertaking reviews in health care, University of York (2009)

19. Kanavos, P., Ross-Degnan, D., Fortess, E., Abelson, J., Soumerai, S.: Chapter 5: Measuring, monitoring and evaluating policy outcomes in the pharmaceutical sector. Eur. Observ. Health Syst. Policies Ser. 1, 97-113 (2004)

20. Rémuzat, C., Urbinati, D., Mzoughi, O., El Hammi, E., Belgaied, W., Toumi, M.: Overview of external reference pricing systems in Europe. J Mark Access Health Policy (2015). https://doi. org/10.3402/jmahp.v3.27675

21. Håkonsen, H., Horn, A.M., Toverud, E.L.: Price control as a strategy for pharmaceutical cost containment-what has been achieved in Norway in the period 1994-2004? Health Policy 90(2-3), 277285 (2009). https://doi.org/10.1016/j.healthpol.2008.09.018

22. Leopold, C., Mantel-Teeuwisse, A., Vogler, S., Joncheere, K., Laing, R., Leufkens, H.: Is Europe still heading to a common price level for on-patent medicines? An exploratory study among 15 western European countries. Health Policy 112(3), 209-216 (2013). https://doi.org/10.1016/j.healthpol.2013.08.012

23. Ruggeri, K., Nolte, E.: Pharmaceutical pricing: the use of external reference pricing. Rand. Health Q. 3, 6 (2013)

24. Business Monitor International: Italy Pharmaceuticals and Healthcare Report-Q3 2009, pp. 1-67. Business Monitor International, London (2009)

25. Business Monitor International: Italy Pharmaceuticals and Healthcare Report-Q4 2009, pp. 1-75. Business Monitor International, London (2009)

26. Business Monitor International: Italy Pharmaceuticals and Healthcare Report-Q3 2010, pp. 1-74. Business Monitor International, London (2010)

27. Business Monitor International: Italy Pharmaceuticals and Healthcare Report-Q2 2010, pp. 1-78. Business Monitor International, London (2010)

28. Business Monitor International: Italy Pharmaceuticals and Healthcare Report-Q1 2010, pp. 1-74. Business Monitor International, London (2010)

29. Lu, C.Y.: The pharmaceutical policy environment and pharmaceutical pricing policies. In: Pharmaceutical Prices in the $21 \mathrm{st}$ Century, pp. 403-411 (2015)

30. Kanavos, P.G., Vandoros, S.: Determinants of branded prescription medicine prices in OECD countries. Health Econ. Policy Law 6(3), 337-367 (2011). https://doi.org/10.1017/s17441331110000 90

31. Business Monitor International: Switzerland Pharmaceuticals and Healthcare Report-Q3 2010, pp. 1-77. Business Monitor International, London (2010)

32. Business Monitor International: Germany Pharmaceuticals and Healthcare Report-Q1 2011, pp. 1-97. Business Monitor International, London (2011)

33. Business Monitor International: Germany Pharmaceuticals and Healthcare Report-Q2 2011, pp. 1-102. Business Monitor International, London (2011)

34. Business Monitor International: Switzerland Pharmaceuticals and Healthcare Report-Q4 2011, pp. 1-88. Business Monitor International, London (2011)

35. Business Monitor International: Switzerland Pharmaceuticals and Healthcare Report-Q1 2012, pp. 1-86. Business Monitor International, London (2012)

36. Houy, N., Jelovac, I.: Drug launch timing and international reference pricing. Health Econ. 24(8), 978-989 (2013)

37. Danzon, P.M., Towse, A.: Differential pricing for pharmaceuticals: reconciling access, $R \& D$ and patents. Int. J. Health Care Financ. Econ. 3(3), 183-205 (2003)

38. Vogler, S., Habimana, K.: Study of the Policy Mix for the Reimbursement of Medicinal Products. Proposal for a Best PracticeBased Approach Based on Stakeholder Assessment. European Commission, Brussels (2014)

39. Vogler, S., Vitry, A., Babar, Z.U.: Cancer drugs in 16 European countries, Australia, and New Zealand: a cross-country price 
comparison study. Lancet Oncol. 17(1), 39-47 (2016). https:// doi.org/10.1016/s1470-2045(15)00449-0

40. Vogler, S., Zimmermann, N., Ferrario, A., Wirtz, V.J., Babar, Z.U.: Challenges and opportunities for pharmaceutical pricing and reimbursement policies. J. Pharm. Policy Pract. 8 (Suppl 1 Abstracts from the 3rd International PPRI Conference), E1 (2015). https://doi.org/10.1186/2052-3211-8-s1-e1

41. Kaló, Z., Docteur, E., Moïse, P.: Pharmaceutical Pricing and Reimbursement Policies in Slovakia. Federal Reserve Bank of St Louis, St Louis (2008)

42. Business Monitor International: Taiwan Pharmaceuticals and Healthcare Report-Q3 2012, pp. 1-100. Business Monitor International, London (2012)

43. Business Monitor International: Taiwan Pharmaceuticals and Healthcare Report-Q3 2014, pp. 1-137. Business Monitor International, London (2014)

44. Business Monitor International: Turkey Pharmaceuticals and Healthcare Report-Q4 2015, pp. 1-127. Business Monitor International, London (2015)

45. OECD: Competition Issues in the Distribution of Pharmaceuticals: Contribution from Romania-Session III. Global Forum on Competition (2014). http://www.oecd.org/officialdocuments/publicdisp laydocumentpdf/?cote $=\mathrm{DAF} / \mathrm{COMP} / \mathrm{GF} / \mathrm{WD}(2014) 30 \&$ docLa nguage $=$ En. Accessed 3 Feb 2014

46. OECD: Competition Issues in the distribution of pharmaceuticals: Background Note by the Secretariat-Session III-Global Forum on Competition (2014). http://www.oecd.org/offic ialdocuments/publicdisplaydocumentpdf/?cote=DAF/COMP/ GF(2014)3\&docLanguage=En. Accessed 3 Feb 2014

47. OECD: Competition Issues in the Distribution of Pharmaceuticals: Contribution from the European Union-Session III-Global Forum on Competition (2014). http://www.oecd.org/officialdo cuments/publicdisplaydocumentpdf/?cote $=\mathrm{DAF} / \mathrm{COMP} / \mathrm{GF} /$ WD(2014)32\&docLanguage $=$ En. Accessed 30 Jan 2014

48. OECD: Competition Issues in the Distribution of Pharmaceuticals: Summary of Discussion. Global Forum on Competition (2014). http://www.fne.gob.cl/wp-content/uploads/2014/09/2014-Compe tition-Issues-in-the-Distribution-of-Pharmaceuticals-289-KB.pdf. Accessed 23 July 2014

49. OECD: Competition Issues in the Distribution of Pharmaceuticals: Contribution from BIAC-Session III-Global Forum on Competition (2014). http://www.oecd.org/officialdocuments/publicdisp laydocumentpdf $/$ cote $=\mathrm{DAF} / \mathrm{COMP} / \mathrm{GF} / \mathrm{WD}(2014) 57 \&$ docLa nguage $=$ En. Accessed 24 Feb 2014

50. Rudisill, C., Vandoros, S., Antoun, J.G.: Pharmaceutical policy Reform in the Russian Federation. J. Health Polit. Policy Law 39(3), 691-705, 615 (2014). https://doi.org/10.1215/036168782682659

51. Mossialos, E., Brogan, D., Walley, T.: Pharmaceutical pricing in Europe: weighing up the options. Int. Soc. Secur. Rev. 59(3), 3 (2006). https://doi.org/10.1111/j.1468-246X.2006.00245.x

52. Barros, P.P.: Pharmaceutical Policies in European Countries. Pharmaceutical Markets and Insurance Worldwide (Advances in Health Economics and Health Services Research 22 (2010). https ://doi.org/10.1108/s0731-2199(2010)0000022004

53. LSE Health/Medical Technology Research Group (MTRG): Survey of Key Experts on the Regulation of Medical Technology. http://www.lse.ac.uk/lse-health/research/mtrg (2017)

54. Akehurst, R., Abadie, E., Renaudin, N., Sarkozy, F.: Variation in health technology assessment and reimbursement processes in Europe. Value Health 20, 67-76 (2017)

55. Jaksa, A., Pontynen, A., Bastian, A.: Exploring the time delay between regulatory approval and health technology assessments (HTAs) of oncology therapies in France, Germany, England, Scotland, Canada, and Australia. J. Clin. Oncol. 35(15_suppl), 6545 (2017). https://doi.org/10.1200/jco.2017.35.15_suppl.6545

56. Jaksa, A., Pontynen, A., Bastian, A.: An exploration of how a countries' HTA process can affect patient access. J. Clin. Oncol. 35(15), e 18052 (2017). https://doi.org/10.1200/jco.2017.35.15_ suppl.e18052

57. Clement, F.M., Harris A, Li, J.J., Yong, K., Yong K, Lee, K.M., Manns, B.J.: Using Effectiveness and Cost-Effectiveness to Make Drug Coverage Decisions: A Comparison of Britain, Australia, and Canada (1538-3598 (Electronic))

58. Nicod, E., Kanavos, P.: Commonalities and differences in HTA outcomes: a comparative analysis of five countries and implications for coverage decisions (1872-6054 (Electronic))

59. Sullivan, S.D., Kanavos, P., Kaló, Z.: Best Practice Principles for External Price Referencing of Medicines; London School of Economics (2019)

Publisher's Note Springer Nature remains neutral with regard to jurisdictional claims in published maps and institutional affiliations. 